La Carta de Crédito y otros medios de pago en el comercio internacional

Óscar Vásquez ${ }^{*}$

Óscar Vásquez realiza un análisis sobre los medios de pago que se pueden utilizar dentro del mercado internacional en conjunto con los riesgos que implica cada uno de ellos para el vendedor.

Gerente Senior de Aduanas y Comercio Exterior de KPMG en Perú. Abogado y Bachiller por la Pontificia Universidad Católica del Perú y Magister en Aduanas y Comercio Exterior por la Universidad de Canberra, Australia. 


\section{La Carta de Crédito y otros medios de pago en el comercio internacional}

\section{Los medios de pago en un contrato de compraventa internacional}

El Comercio Internacional es una actividad en la que posee vital importancia la manera de pago y cobro de las compraventas internacionales, exportaciones e importaciones, con el añadido de que dada la complejidad de las operaciones que se realizan, el escoger la forma de pago más eficiente, es decir la que permita obtener la máxima seguridad del cobro a los menores costos posibles, según el tipo de operación o partes involucradas, es base para la obtención de precios competitivos que permitan la entrada a mercados extranjeros.

Una de las preocupaciones que se generan en los participantes en un contrato de compraventa internacional, especialmente en el Vendedor de la mercancía, está referida al cumplimiento de la obligación de pago; así como el riesgo de no conformidad de entrega de las mercancías es la preocupación del Comprador. Esto se debe a que en general, las partes contratantes desconocen el grado de solvencia de su contraparte, además de que, a diferencia de la compraventa local, la internacional no se realiza mediante el cumplimiento simultáneo o inmediato de las prestaciones comprometidas.

Sin embargo, la costumbre y los usos del comercio internacional han ido creando una gran variedad de medios de pago que aseguran al Vendedor el pago a cargo del Comprador, a costos que tienen una relación directa con el nivel de seguridad, es decir que mayor nivel de seguridad en el pago implicará un costo más alto.

En este sentido, siempre el acceso a medios de pago a través de entidades bancarias o financieras va a significar gastos relativamente altos y procedimientos complejos, además debe tenerse en cuenta que los créditos documentarios requieren una gestión de documentos impecable.

Estos medios de pago se encuentran a disposición de los agentes comerciales para que establezcan, según su conveniencia, el tipo de medio de pago más eficiente para su transacción, utilizando variables como, por ejemplo, el nivel de confianza que tengan con sus Compradores, con el cual pudieran establecer sistemas más sencillos y económicos cuanto más conocidos y confiables sean.

Los usos y co stumbres internacionales del comercio internacional, tal como sucede con muchas otras actividades que le pertenecen, han producido que los medios de pago tengan como su sustento normativo, reglas que han sido compiladas por diversas instituciones y organismos especializados a nivel internacional, que además se encargan de dar pautas y compilar la costumbre internacional en reglas, como es el caso de la ICC (Cámara de Comercio Internacional), siendo su trabajo de mucha ayuda. 
Las prestaciones debidas en un contrato de compraventa internacional de mercaderías son, por un lado, la entrega del bien o bienes, y por el otro, la obligación del pago del precio.

La entrega del bien puede realizarse por los medios de transporte conocidos (terrestre, marítimo, aéreo, multimodal, vía courier), teniendo en cuenta el tipo de mercancía y la rapidez con la que se desee contar con la mercancía en cuestión (el precio de cada tipo de servicio de transporte se ponderará según esta necesidad).

Debe entenderse que una compraventa internacional propiamente dicha está referida a la operación en la que solamente la mercancía atraviesa las fronteras estatales mientras que las partes, Comprador y Vendedor permanecen en sus respectivos países (a diferencia del caso de un contrato de compraventa simple o local).

La idea de que esto suceda así es minimizar los costos de transacción evitando que las Partes deban encontrarse físicamente juntas en un mismo lugar, teniendo que incurrir en costos de viajes de los representantes por ejemplo.

Teniendo en cuenta ello, los usos y costumbres han creado cuatro formas de pago que implican diferentes riesgos para vendedor y comprador:

\section{Efectivo por Adelantado}

Es el método de pago más rudimentario en la Compraventa Internacional. En esta operación, el Comprador de la mercancía paga el precio al Vendedor antes del embarque de la mercancía (por adelantado), sin adquirir todavía el control sobre los bienes y sacrificando liquidez.

En esta forma de pago es el Vendedor quién posee todas las ventajas, ya que cuenta por adelantado con el precio de la mercancía. Antes de empezar a cumplir la prestación principal a la que se ha comprometido (entrega del bien), ve satisfecho su interés (el cobro del precio) y puede determinar el momento del embarque de la mercancía según le convenga, antes del vencimiento de su obligación, sin embargo se le ha financiado por adelantado. Por lo tanto, el riesgo del incumplimiento se encuentra sólo en el Comprador.

La ventaja para ambas Partes de utilizar este medio de pago se encuentra en que no incurrirán en el pago a algún Banco para que intervenga en la transacción.

Es definitivamente el sistema más seguro para el Vendedor, pero en los mercados competitivos su uso no es común, se da a veces concediéndose algún descuento sobre el precio de la mercancía.

Este medio de pago se utiliza cuando existe una gran confianza entre las empresas porque el Comprador está sometido a un gran riesgo por lo que no debe aceptar hacer uso de este medio de pago sin disponer de información completa sobre la buena 
reputación de su Vendedor. Asimismo, las Partes deberán asumir el riesgo de la variabilidad de la tasa de cambio de la moneda que se utilice en el pago.

Ciertos instrumentos de pago documentarios, como las Cartas de Crédito con "Cláusula Roja", constituyen variantes de Pagos por Adelantado.

\section{Cuenta Abierta}

Por este medio de pago el Vendedor de los bienes debe embarcarlos sin recibir el pago ni retener los derechos sobre los bienes. El pago del precio se realizará posteriormente, una vez que el Comprador haya recibido la mercancía y esté conforme con ella.

Este medio de pago es el revés del pago "Efectivo por Adelantado", ya que en este caso el Comprador es quién tiene todas las ventajas y ningún riesgo.

En este caso, el Vendedor debe financiar y sacrificar liquidez y esperar que el Comprador cumpla con la obligación de pago del precio; éste podrá pagar cuando le sea conveniente, siempre que cumpla con lo estipulado en el contrato.

Por lo tanto, el riesgo por incumplimiento contractual se encuentra totalmente en el Vendedor, que en caso de producirse un atraso o incumplimiento solamente podrá sancionar al cliente con la pérdida de este beneficio en el futuro.

Tal como se puede observar, en esta forma de pago tampoco es necesaria la intervención de un Banco, por lo que los costos siguen siendo mínimos, pero implica un grado de confianza importante entre las Partes; puede tratarse, por ejemplo, del caso de clientes habituales, o de que ambas Partes pertenecen al mismo grupo empresarial, etc.

También suele suceder que el Vendedor conceda crédito al Comprador pero previo otorgamiento de una garantía para varias operaciones, y si el Comprador no paga una Factura, el Vendedor pueda efectivizar el importe de la garantía.

A través de este sistema, el Vendedor envía la mercancía, la factura comercial y los documentos de embarque a la empresa compradora y a continuación aguarda el pago; es decir, es en la práctica una compraventa a crédito.

El Vendedor debe aceptar este sistema únicamente si tiene confianza absoluta en su cliente, y en la estabilidad y la legislación del país de su comprador. Debe tenerse en cuenta que en un mercado inestable, una caída súbita de los precios puede llevar a los Compradores a intentar eludir sus obligaciones contractuales.

Por otro lado las condiciones de cuenta abierta son muy ventajosas para las empresas compradoras, ya que no tienen que pagar la mercancía hasta que la reciben y verifiquen que esté conforme con lo solicitado. Incluso podrían vender la mercancía y emplear el dinero para pagar la factura comercial del Exportador cuanto ésta finalmente llegue. 


\section{Cobro mediante documentos}

En un Cobro mediante Documentos los bienes son embarcados al Comprador, sin embargo un Banco mantendrá en custodia los documentos de embarque necesarios para desaduanar la mercancía, y sólo los entregará al comprador de la mercancía cuando se ejecute la prestación a su cargo: el pago por la mercancía o la firma de una letra de cambio.

Cabe resaltar que por este medio de pago los Bancos no asumen ningún riesgo de crédito y solamente actúan como agentes.

Esta forma de pago tiene como ventajas para el Comprador, el que éste puede rehusarse a pagar el precio o a aceptar la Letra de Cambio, si una vez que la mercancía se encuentra en la aduana de destino, tiene noticias acerca de su deterioro o pérdida durante el transporte o en caso no se encuentre conforme con ella.

Y tiene como ventaja para el Vendedor, el que éste controla hasta el pago del precio, a través del Banco, la entrega de los documentos necesarios para el desaduanaje de la mercancía. Sin embargo, mediante este medio de pago, el Vendedor debe asumir el riesgo de que el Comprador no pague o no acepte los documentos.

Además, el Banco no brinda este servicio gratuitamente, sino que cobra por él, por lo que la seguridad en el cobro (riesgo) es un costo que deberá asumirse como parte de los costos de transacción, lo que al final incrementa el precio de venta final de los productos. Sin embargo sin ser tan seguro como el Crédito Documentario, es significativamente más económico.

Mientras que el Pago por Adelantado representa la opción ideal para el Vendedor y la Cuenta Abierta es la ideal para el Comprador, la Cobranza Documentaria, al igual que el caso del Crédito Documentario, son compromisos que ofrecen beneficios a ambas Partes.

Como vemos, la Cobranza Documentaria permite que el Comprador mantenga el control de la mercadería hasta que recibe el pago o una garantía de que lo recibirá. Embarca la mercancía y reúne los documentos comerciales, como la factura comercial y el conocimiento de embarque, y los entrega a un Banco que actúa como su agente. Este Banco sólo entregará estos documentos al Comprador si éste paga contra el documento o acepta la obligación de hacerlo en una fecha determinada.

Como mínimo, en esta operación participan los siguientes Bancos: el Banco del Vendedor (Banco Remitente) y un Banco en el país del Comprador (Banco Cobrador o Banco Presentador) que presenta los documentos para cobrarlos.

Esta cadena de información hace necesario que las instrucciones del Vendedor se llenen cuidadosamente en un formulario de cobranza que sirve al Banco para preparar la Orden de Cobro que envía al Banco Cobrador con la Cobranza Documentaria. 


\subsection{Definición}

Las Cobranzas Documentarias, denominadas también en forma indistinta "Cobros", "Cobro de remesas", o "Gestión de Cobro de Documentos", se refieren a aquella operación por la cual el Vendedor presenta y entrega determinados documentos comerciales $\mathrm{y} / \mathrm{o}$ financieros a su Banco con instrucciones expresas para su cumplimiento, que pueden ser el pago o la aceptación de una Letra de Cambio.

Las operaciones de Cobranzas Documentarias están reguladas por las R.U.U. (Reglas y Usos Uniformes) relativas a las Cobranzas (Publicación No. 522) de la Cámara de Comercio Internacional.

Según las RUU No. 522 se entiende por "Collection" (Cobranza) a la tramitación por parte de los Bancos, de documentos, de acuerdo con las instrucciones recibidas, a fin de obtener el pago y/o la entrega de una letra de cambio y otros documentos, según los términos y condiciones.

Las Cobranzas (junto con los Créditos Documentarios) son las operaciones más utilizadas en el comercio exterior, pues permiten al Vendedor mantener los documentos en custodia de los Bancos hasta que las condiciones hayan sido cumplidas por el Comprador; esto quiere decir que los documentos de la mercancía no serán entregados si el pago por la misma no se ha efectuado.

El Folleto No. 522 con el término "Documentos" hace referencia a dos clases de documentos: documentos financieros y a documentos comerciales.

Los documentos financieros o "financial documents" son letras de cambio, pagarés, cheques $u$ otros instrumentos utilizados para obtener el pago.

Los documentos comerciales o "commercial documents" son la factura comercial, los documentos de transporte, documentos de título u otros documentos análogos que se pretenden cobrar.

\subsection{Partes intervinientes}

Conforme al Folleto No. 522, intervienen las siguientes Partes en la Cobranza Documentaria:

- El Cedente o Principal, quién encomienda a un Banco la tramitación de una cobranza.

- El Banco Remitente o "Remitting Bank", que es el Banco al cual el Cedente encomienda la tramitación de una Cobranza.

- El Banco Cobrador o "Collecting Bank", que es cualquier Banco, distinto del Banco Remitente, que interviene en la tramitación de la Cobranza. 
- $\quad$ El Banco Presentador o "Presenting Bank", que es el Banco Cobrador que efectúa la prestación al Librado.

- El Librado o "Drawee" quién es la persona a quién debe efectuarse la presentación de los documentos y requerir el pago, de acuerdo con las instrucciones de la Cobranza.

\subsection{Operatividad}

Todos los documentos enviados deben ir acompañados de instrucciones precisas y completas que indiquen que la Cobranza está sujeta a las R.U.U. No. 522 de modo que los Bancos sólo estén autorizados a actuar según las instrucciones contenidas en las instrucciones de cobro y conforme a la referidas Reglas.

Las R.U.U. nos dicen que las instrucciones deberán contener la siguiente información:

- Los detalles del banco que recibió la cobranza, el nombre completo, las direcciones postales, SWIFT, teléfono y fax, y la referencia.

- $\quad$ Los detalles del cedente, el nombre completo, la dirección postal y, los números de teléfono y fax.

- Los detalles de librado, incluyendo el nombre completo, la dirección postal o el domicilio donde deberá efectuarse la presentación, y, los números de teléfono y fax.

- Los detalles del banco presentador, si lo hubiere, el nombre completo, la dirección postal, y, de ser el caso, los números de teléfono y fax.

- $\quad$ El importe y la moneda objeto del cobro.

- $\quad$ La relación de los documentos que se adjuntan y el número de ejemplares de cada uno de ellos.

- $\quad$ Los términos y las condiciones para la obtención del pago y/o la aceptación.

- $\quad$ Las condiciones de entrega de los documentos contra: 1) pago y/o aceptación; 2) otros términos y condiciones. Es importante mencionar que las R.U.U. No. 522 señalan que la Parte Remitente de la instrucción de cobro es responsable de que los términos de entrega de los documentos aparezcan mencionados de forma clara y sin ambigüedad, de lo contrario los Bancos no serán responsables de las consecuencias que de ello pudiera derivarse.

- $\quad$ Los cargos a cobrar, indicando si pueden ser rehusados o no.

- Los intereses a cobrar indicando si pueden ser rehusados o no, incluyendo: tasas de interés, periodo de liquidación de intereses, base de cálculo. 
- $\quad$ El método de pago y la forma de aviso del mismo.

- Las instrucciones a seguir en caso de falta de pago, no aceptación y/o incumpliendo de cualquier otra instrucción.

- La dirección completa del librado o el domicilio donde debe efectuarse la presentación. Si la dirección es incompleta o incorrecta el banco cobrador puede, sin compromiso o responsabilidad de su parte, intentar averiguar la dirección correcta, sin embargo, el banco cobrador no tendrá obligación ni responsabilidad alguna por cualquier demora que pudiera producirse como consecuencia de una dirección recibida de forma incompleta o incorrecta.

Es importante mencionar que en el caso de documentos pagaderos a la vista, el banco presentador deberá efectuar sin demora la presentación de los mismos para el pago y si se tratase de documentos pagaderos de una forma distinta, el banco presentador deberá presentarlos sin demora para la aceptación, y cuando se requiera el pago deberá presentarlos a más tardar la fecha de vencimiento correspondiente.

\subsection{Reglas aplicables: RUU No. 522}

Las referidas reglas se aplicarán siempre que así se establezca en las Instrucciones de Cobro (Collection Instructions). En consecuencia, si las partes convienen en aplicar estas Reglas, se obligan por ellas, salvo que hayan convenido su aplicación de forma parcial de manera expresa, o cuando las reglas sean contrarias a la Ley, la cual no puede ser contravenida.

\subsection{Ventajas y desventajas de las cobranzas}

Para el Vendedor, las ventajas de las Cobranzas son la sencillez, el bajo costo y el control sobre los documentos de transporte que mantiene hasta que reciba garantías del cobro.

Para el Comprador, las ventajas son que no tiene obligación de pagar antes de haber podido examinar los documentos $y$, en algunos casos incluso la mercancía (en un almacén aduanero por ejemplo).

Las desventajas para el Vendedor son que corre el riesgo de que el Comprador no acepte la mercancía, el riesgo de crédito del Comprador, el riesgo político del país del Comprador y asimismo, de que la mercancía no pueda despacharse en la Aduana. Una desventaja más es que el mecanismo de la cobranza puede resultar relativamente lento para el Vendedor.

El riesgo que corre el Comprador es el de recibir mercancía que no corresponda con las especificada en la factura o en el conocimiento de embarque, pero este factor es inevitable a menos que exija un certificado de inspección previa al embarque, otorgado por una empresa supervisora, como parte de la documentación. 
Es importante mencionar que ningún Banco asume ningún riesgo en las Cobranzas Documentarias, sin perjuicio de los que se deriven de su negligencia en el cumplimiento de las instrucciones recibidas.

\section{El Crédito Documentario y la Carta de Crédito}

\subsection{El Crédito Documentario}

\subsubsection{Principios de los Créditos Documentarios}

\subsubsection{Independencia del Crédito Documentario respecto al contrato de compraventa internacional subyacente}

El Crédito Documentario es totalmente independiente del subyacente, que es el contrato de compraventa internacional de mercadería firmado entre Comprador y Vendedor.

El contrato bancario de Crédito Documentario es uno cuyas partes son el Banco y su cliente, que suele ser el Comprador de la mercancía y/o responsable del pago según el contrato de compraventa internacional.

El Vendedor no es parte de este contrato bancario, solamente es un tercero beneficiario, quién luego de cumplir con las cargas estipuladas en la Carta de Crédito a su favor, podrá hacerla efectiva.

Tiene asimismo la potestad de aceptar o no la Carta de Crédito y las condiciones que ella estipula.

Por lo tanto, si el Vendedor cumple con las cargas de presentación de documentos señalados en las instrucciones, el pago deberá efectuarse de acuerdo con los Términos del Crédito, independientemente de las disputas relacionadas con el contrato subyacente.

La única excepción es una prueba clara de que el Beneficiario ha cometido Fraude y, de acuerdo a los cauces legales, el Banco podrá retener el pago, pero no se exige que realice investigaciones por su cuenta sobre sospechas de Fraude. Por otro lado, los Tribunales son bastantes reacios a emitir mandatos judiciales para ordenar a un Banco que retenga un pago, por lo que se requieren indicios evidentes de Fraude. Pero ésta es una excepción.

El uso de las Cartas de Crédito tiene su origen justamente en la necesidad de evitar riesgos cuando no existe confianza entre Comprador y Vendedor, de allí que es imprescindible que ambos se puedan fiar de los Bancos. El Sistema de Créditos Documentarios no funcionaría si las empresas no depositan su confianza en él. Por ello, los Bancos deberán cumplir con las obligaciones a las que se han comprometido 
sin importar los argumentos en contra que puedan presentar posteriormente sus clientes.

Incluso, en el caso de que el Vendedor enviase mercancía defectuosa y ello no se evidencie de los documentos presentados al Banco que los declara Conformes, el Comprador solamente tendrá el recurso de la demanda judicial por daños y perjuicios producidos por el incumplimiento del contrato de compraventa internacional.

\subsubsection{Cumplimiento Estricto}

Los documentos que se presentan deben corresponder de manera exacta con los Términos del Crédito Documentario.

Las decisiones de los Bancos, relacionadas con las Discrepancias deberán basarse en el Principio de Cumplimiento Estricto.

En efecto, en un Crédito Documentario, el Banco Emisor actúa como agente del Comprador y por lo tanto deberá seguir las instrucciones que éste le ha dado, por ello, los Bancos deberán preocuparse de que los documentos sean absolutamente correctos.

Si un Banco pagase un Crédito Documentario incumpliendo las instrucciones dadas, va a encontrarse con un Ordenante que se niegue a reembolsarle el pago, por ello en la práctica los Bancos son muy quisquillosos en la revisión de los documentos. No podría esperarse otra cosa porque los funcionarios del Banco no son expertos en Compraventas Internacionales, tampoco conocen ciertos términos técnicos, ni tendrían porque saber que una palabra que a simple vista suena común puede tener gran importancia para la operatividad del contrato.

Por otro lado, es difícil formular una regla que decida lo "importante" o "leve" que ha de ser un error para que se consideremos que estamos frente a un Discrepancia.

La transcendencia de un error ortográfico o numérico, por ejemplo, es una fuente de disputas. Por ello, las empresas exportadoras deben comprobar cuidadosamente que la descripción y la redacción de la Factura Comercial sea perfecta y en conformidad con el Crédito Documentario.

Sin perjuicio de ello, luego de hecha la consulta a su cliente, el Banco puede levantar la Discrepancia en los documentos, algo que sucederá con toda seguridad si el Comprador quiere la mercancía, porque sino tampoco obtendrá los documentos necesarios para realizar el desaduanaje.

\subsubsection{Definición RUU 600}

Los Créditos Documentarios no están regulados por el ordenamiento jurídico peruano, por lo tanto, resulta necesaria hacer referencia a las "Reglas y Usos Uniformes relativos 
a los Créditos Documentarios", elaboradas por la Cámara de Comercio Internacional, aplicables desde el 1 de julio de 2007.

Estas Reglas no forman parte de un Tratado firmado por nuestro país que se haya incorporado a nuestro ordenamiento jurídico. Son meras reglas informativas para completar las relaciones contractuales y facilitar el comercio internacional.

Son un conjunto de usos y costumbres recogidos por una institución, la Cámara de Comercio Internacional (CCI), con el fin de que a los operadores y agentes del comercio internacional se les haga más fácil y segura su actividad, pero es muy discutible que puedan calificarse como componentes del ordenamiento jurídico peruano porque no son tratado Internacional, sin embargo es indudable su utilidad para facilitar los pagos y cobros entre las empresas importadoras y exportadoras.

Las "Reglas y Usos Uniformes Relativos a los Créditos Documentarios" fueron publicadas por primera vez en 1929, por la Cámara de Comercio Internacional, la cual posteriormente introdujo revisiones en los años 1933, 1951, 1962, 1974, 1983, 1994 y 2007. Las reglas en vigor a la fecha están en el Folleto No. 600 de 2007.

Estas revisiones introdujeron cambios con la intención de mejorar las reglas anteriores, usando un lenguaje más claro y preciso, y utilizando las experiencias adquiridas en la aplicación de las anteriores versiones, introduciendo además adaptaciones según las tecnologías modernas, sin embargo, la naturaleza de esta operación no ha variado mucho desde su versión más antigua.

Por su parte, la aceptación de las reglas y usos establecidos por la Cámara de Comercio Internacional ha sido universal y ha facilitado enormemente la utilización de los Créditos Documentarios, así como ha servido para la resolución de litigios y diferencias de interpretación.

La Reglas 600 de la ICC, Reglas y Usos Uniformes Relativos a los Créditos Documentarios ("RUU 600" o "UCP 600" del inglés Uniform Customs and Practice) han estandarizado en el mundo, los usos y prácticas de las Cartas de Créditos Internacionales.

Asimismo, las RUU son el acto de armonización mercantil de más éxito en la historia del comercio internacional, y un ejemplo de cómo la autorregulación del comercio internacional puede resultar más eficaz que los tratados, las leyes de un país o la jurisprudencia.

La primera versión de las RUU es de 1929, pero fue la edición de 1933 la que obtuvo amplia aceptación en Europa. La siguiente revisión de las Reglas se aprobó en 1951, y las llevó a un uso internacional, ya que las empezaron a utilizar Bancos de Asia, África y América. La revisión de 1962 se ganó la aceptación de la influyente comunidad financiera del Reino Unido y los países de la Commonwealth. Las revisiones 
posteriores, con mejoras técnicas, se publicaron en 1974 y 1983 , y posteriormente, las RUU 500 entraron en vigencia el 1 de enero de 1994, y las vigentes, las RUU 600, están vigentes desde el 1 de julio de 2007.

Las RUU forman un conjunto de normas más flexibles que cualquiera legislación, no teniendo la rigidez de un Tratado, dado que las RUU se pueden incluso utilizar sólo parcialmente. Por su parte, la redacción de un Tratado Internacional, incluyendo la ratificación de los países firmantes, puede llevar décadas.

Las RUU, por el contrario, no son ley de cumplimiento obligatorio pero se aplican porque los Bancos las incorporan voluntariamente en los contratos de sus créditos documentarios.

Las RUU adoptan por escrito los usos y costumbres del mundo comercial, basados en la experiencia de los Bancos y de las empresas exportadoras e importadoras. Asimismo, las revisiones periódicas han permitido que las RUU se mantengan al día de los avances en las costumbres bancarias.

Sin embargo, el principio básico es que las RUU son producto de la libre contratación y, por tanto, se aplican solamente cuando las Partes las incorporan voluntariamente. Así pues, las solicitudes de aperturas de Créditos Documentarios incluyen generalmente una declaración que los somete a las RUU 600, este hecho, legalmente, se considera como la prueba de que las partes contratantes desean someter la interpretación del Crédito a las RUU.

Cabe señalar que tras más de 80 años de existencia, las RUU han alcanzado un nivel tal de vigencia universal que en algunos países se les reconoce como Costumbre Mercantil Internacional, lo que las convierte en fuente de derecho.

\subsubsection{Naturaleza Jurídica}

El Crédito Documentario es un contrato bancario que tiene algunas de las características de la Orden de Pago y algunas de la Garantía, sin embargo, es importante dejar claro el carácter financiero que lo distingue y lo hace totalmente independiente del contrato comercial existente entre el Comprador y el Vendedor de la mercancía.

La doctrina ha intentado buscar semejanzas entre el Crédito Documentario y otras instituciones clásicas como el Mandato, la Fianza o la Delegación, encontrándose diferencias mayores de lo que se piensa. Asimismo, se le confunde con la Carta de Crédito, que es el documento a través del cual se implementa el contrato de crédito documentario. 
Alberto Asquini entendía que el Crédito Documentario era un Mandato, en el cual las partes eran el Comprador de la mercancía, como Mandatario, y el Banco ${ }^{1}$. Sin embargo, a diferencia del Mandato, en el Crédito Documentario existe un compromiso autónomo del Banco en el que éste no actúa como un representante sino que se obliga personalmente, nos dice el Dr. Aníbal Sierralta².

Por su parte, para el francés Escarra ${ }^{3}$, estamos frente a una Delegación, así el Delegante era el solicitante de la emisión de la Carta de Crédito que reunía las personas de Acreedor y de Deudor, pues, al comprar debe el precio y al abrir el Crédito, se convierte en Acreedor del Banco, pero como es quién deberá pagar al Vendedor, le delega al Banco la obligación de pagar, teniendo el Banco una posición parecida a su intervención en la Letra de Cambio.

Por su parte, Hamel niega esta naturaleza del Crédito Documentario señalando que en este contrato no existe aceptación expresa por parte del Banco de la delegación indicada. Para Hamel, estamos frente a una relación compleja, y a un contrato híbrido y nuevo, posición seguida por los autores más recientes, entre los que nos encontramos.

Para Josserand se trata de una Novación consistente en la sustitución convencional de una obligación por la otra: la relación jurídica antigua queda extinguida por el nacimiento de otra nueva que ocupa su lugar; una obligación desplaza a la otra. Sin embargo para que exista una novación sería necesaria la manifestación indubitablemente de la voluntad del Acreedor, cosa que no sucede en el Crédito Documentario donde el Acreedor (Vendedor) sigue teniendo como contraparte a su mismo Deudor (Comprador), aunque acepta que sea a través del Banco que se realice el pago convenido con el primero, pero no acepta en ningún momento la extinción de la relación obligatoria con el Comprador de la mercancía.

Otro sector de la doctrina considera al Crédito Documentario como una Cesión de Créditos hecha por el Ordenante (Comprador) al Beneficiario (Vendedor). En este sentido, el Crédito original sería el surgido en beneficio del Ordenante y en contra del Banco en virtud del contrato de Apertura del Crédito Documentario. Sin embargo debe recordarse que en la Cesión de Créditos, el Deudor puede oponer al Acreedor Cesionario las excepciones que pudiera haber opuesto al Cedente, lo que no es viable en el Crédito Documentario.

También se ha dicho que el contrato de crédito documentario es en realidad una Fianza, definido como un contrato formal, accesorio, oneroso y de garantía, según el

1 Sierralta, Aníbal, "Origen y Naturaleza Jurídica de los Créditos Documentarios". En: Themis, №. 35, Lima, p. 24.

Ídem, p. 25.

Ídem, p. 24. 
cual el Fiador se obliga frente al Acreedor a pagar la obligación garantizada, una vez que sea exigible y no haya sido satisfecha por el Fiador.

En este caso, sin embargo, la fianza no explica todas las relaciones obligatorias independientes que surgen del contrato de crédito documentario, ni la situación de las excepciones que no pueden ser deducidas por la institución financiera respecto de la obligación principal que no caben en el Crédito Documentario.

Asimismo, la Fianza supone, antes de ser ejecutada, que se demuestre fehacientemente que el Deudor principal no ha cumplido con sus obligaciones contractuales. En el Crédito Documentario, el razonamiento es el al revés, pues para la ejecución de la Carta de Crédito, bastará que el Beneficiario cumpla con los cargos a los que se ha comprometido.

En este sentido, cuando hablamos del Crédito Documentario estamos frente a un contrato propio tal como los señalaba Hamel.

\subsection{La Carta de Crédito}

\subsubsection{Definición}

El Crédito Documentario es un instrumento de crédito por el cual un Banco se compromete, por orden de su Cliente, a poner a disposición de un Beneficiario, con quién no tiene ninguna relación contractual previa, una determinada cantidad de dinero, generalmente por medio de otro Banco (Banco Corresponsal), haciendo entrega de un documento llamado Carta de Crédito, que puede ser transferido por vía de endoso.

El origen primitivo de la operación se encuentra en un contrato de compraventa internacional previo que motiva que uno de los sujetos celebre un contrato de apertura de crédito que tiene un carácter especial respecto de las relaciones jurídicas que de él van a resultar, ya que uno de los sujetos (el Banco) se torna, en su propio nombre, Deudor del Comprador, con quién no tenía relaciones precedentes.

Dicho Banco asume la obligación de pagar al Vendedor sin analizar el contrato de compraventa contra la exhibición de los documentos especificados por el Solicitante del Crédito (su cliente, el Comprador de la mercancía).

El Banco, en la operación internacional, colocará la cantidad correspondiente a disposición en la plaza del Vendedor, avisándole generalmente a través de una agencia que tenga en dicha plaza, o de otro Banco (Advising Bank).

Pero, ¿es la Carta de Crédito un medio de pago o un título valor?

Si la Carta de Crédito fuera un medio de pago, significaría que su aceptación extinguiría la obligación principal del pago de precio del contrato de compraventa internacional, a cargo del Comprador, transmitiéndose esta obligación al Banco. 
Nos encontraríamos en este caso con una novación subjetiva, cuya condición es una declaración indubitable de la conformidad del Acreedor, en este caso del Comprador de la mercancía.

Sin embargo, esta declaración indubitable que permitiría el traslado del Obligado a cumplir la obligación de pago, no se produce.

Respecto a si se trata de un título valor, tenemos que éste es un documento acreditativo de un derecho de crédito patrimonial cuyos principios son: el Principio de Incorporación, el de Literalidad, el de Autonomía, el de Destino Circulatorio, y el de Legitimación, cumpliéndose con todos excepto con éste último, dado que por este Principio debiera existir un reconocimiento legal para que un documento sea título valor, y esto es porque solamente por el Imperio de la Ley podría ordenarse su cobro mediante el Proceso Judicial preferencial correspondiente a todos los títulos valores.

El contrato de crédito documentario es un negocio jurídico entre el Banco y su Cliente, y la Carta de Crédito, es el documento que nace de la celebración de dicho contrato, y que otorga el Banco al Beneficiario indicado por su Cliente.

En este sentido, la Carta de Crédito no es un medio de pago por sí mismo, ni tampoco un título valor.

\subsection{Operatividad del Crédito Documentario y la Carta Crédito}

Como hemos visto, una Carta de Crédito es un documento emitido por un Banco, a pedido de su Cliente por el cual el Banco se compromete a otorgarle un crédito al Comprador para que pague al Vendedor, y se cumpla con el pago de precio y se extinga dicha obligación. El acuerdo entre el Banco y su Cliente es el contrato bancario de crédito documentario.

El Crédito Documentario sirve como medio de financiación del comercio internacional y garantiza, mediante la intervención de uno o más Bancos, el pago del precio y la recepción de las mercancías.

El problema en el comercio internacional es que el Comprador no querrá pagar el precio de la mercadería sin tener cierta seguridad o garantía sobre la Entrega y el Estado de las mercancías; y el Vendedor no querrá desprenderse de las mismas sin asegurar el Cobro del Precio o la Entrega de un título valor. Sin embargo, en virtud de este contrato, y por medio de una entidad bancaria o más de una, el Vendedor se asegura el cobro del precio y, a su vez, el Comprador se asegura, la posesión mediata y disponibilidad de las mercancías, a través de los documentos representativos de las mismas.

Sin perjuicio de ello, las tarifas bancarias pueden resultar relativamente caras. Además, el Vendedor debe contar con un sistema riguroso de preparación de documentos para 
evitar el riesgo de no pago por falta de conformidad en los mismos, cuando los presente al Banco.

\subsubsection{Definición según la Cámara de Comercio Internacional (ICC)}

La Cámara de Comercio Internacional en las nuevas Reglas y Usos Uniformes relativos a los Créditos Documentarios (RUU N0600) no nos da una definición de Crédito Documentario, sin embargo, las RUU No. 500 (la versión anterior) tenían en su Artículo 2, la siguiente definición de Crédito:

"A efectos de los presentes artículos, las expresiones "Créditos/s Documentarios/s" "Carta/s de Crédito Stand by" (en adelante "Créditos/s"), se refieren a todo acuerdo, cualquiera sea su denominación o descripción, por el que un banco ("Banco Emisor"), obrando a petición y de conformidad con las instrucciones de un cliente ("Ordenante") o en su propio nombre:

Se obliga a hacer un pago a un tercero ("Beneficiario") o a su orden, o a aceptar pagar letras de cambio (instrumentos/s de giro) librados por el Beneficiario, o,

Autoriza a otro banco para que efectué el pago, o para que acepte y pague tales instrumentos de giro, 0 ,

Autoriza a otro banco para que negocie, contra la entrega del/de los documento/s, siempre y cuando se cumplan los términos y las condiciones del Crédito." 4

Esta errada definición generaba una confusión necesaria de resolver, puesto que, no es lo mismo el Crédito Documentario, que es el contrato entre el Banco y su Cliente (generalmente el Comprador), y en el cual no participa el Vendedor de la mercancía; y la Carta de Crédito, que es el documento que le otorga el Banco al Vendedor porque el contrato bancario de crédito documentario así lo ordena.

\subsection{2 ¿Cómo funciona la Carta de Crédito?}

El funcionamiento del Crédito Documentario - Carta de Crédito para el pago y/o financiamiento de una operación de compraventa internacional (contrato subyacente) se inicia con la Solicitud del Comprador (Ordenante) a un Banco (Banco Emisor) para que en nombre propio pero por cuenta del Ordenante abra una Carta de Crédito a favor del Vendedor (Beneficiario).

4 http://www.e-camara.net/revista/2285/comercio_exterior.htm, Folleto 500, Artículo 2, 21 de septiembre de 2015. RUU - Cámara de Comercio Internacional. 
El Banco Emisor, en base al contrato bancario de crédito documentario, asume el compromiso de pagar contra entrega, por parte del Beneficiario, de la documentación previamente acordada (documentos de transporte, documentos de seguro, facturas comerciales, etc.)

Si el Banco Emisor no tiene sucursal en el domicilio del Vendedor, suele participar otro Banco situado en el país del Vendedor, que actúa bien como Banco Notificador o Avisador (solamente como un correo del Banco Emisor y no asume ninguna obligación propia), como Banco Designado o Pagador (recibe los documentos y paga en nombre del Banco Emisor), o como Banco Confirmador (recibiendo documentos y pagando en nombre propio, porque se vincula directamente con el Beneficiario asumiendo un compromiso directo con él).

\subsubsection{Partes}

Los sujetos intervinientes en una operación de Crédito Documentario - Carta de Crédito son:

- $\quad$ Ordenante o Solicitante: Es quién solicita a un Banco la apertura de una Carta de Crédito a favor del Beneficiario y es quién asume el pago del importe de la transacción por el cual la Carta de Crédito es emitida.

El Ordenante suele ser el Comprador de la mercancía, pero a veces es un Agente Intermediario que actúa por cuenta de éste para cursar las instrucciones al Banco para la apertura del Crédito.

- $\quad$ Beneficiario: Es la persona o empresa en cuyo favor se abre una Carta de Crédito y que tiene la garantía de que cobrará el importe de la operación si presenta, en tiempo y forma, los documentos requeridos por el Ordenante. El Beneficiario suele ser el Vendedor de la mercancía.

- Banco Emisor: Es el Banco o Entidad Financiera que, a solicitud del Ordenante, abre una Carta de Crédito a favor del Beneficiario, persona natural o jurídica, asumiendo el compromiso de pago siempre que se presenten correctamente los documentos específicos.

Puede dejar de ser solamente un Banco Emisor para convertirse en Banco Ordenante, si instruye a otro Banco para que abra el Crédito por orden suya.

- Banco Notificador o Avisador: Dado que el Banco Emisor suele estar situado en el mismo país que el Ordenante, suele concertarse con otro Banco (domiciliado en el país del Beneficiario) para que comunique al Beneficiario la apertura del Crédito a simple título informativo, esto quiere decir que no contrae ninguna responsabilidad más que la de autenticar las firmas que suscriben la apertura y 
enviar una copia al Beneficiario. Lo normal es que también se encargue de recibir los documentos solicitados en el Crédito y que los remita al Banco Emisor.

- Banco Confirmador: El Banco Emisor puede pedir al Banco Notificador, o a otro distinto, que confirme el Crédito para que este Banco asuma, en nombre propio, el compromiso de pago, quedando obligado de forma solidaria con el Banco Emisor.

- Banco Negociador: Es el Banco que descuenta la Carta de Crédito girada por el Banco Emisor, esto es que adelanta fondos contra la presentación de los documentos conformes, según las instrucciones del Crédito.

- Banco Designado o Pagador: Es el Banco que está autorizado para efectuar el pago al Beneficiario.

Tal como hemos visto, un Banco puede asumir una o más funciones en una sola transacción.

En la mayoría de las operaciones de comercio internacional participan por lo menos dos Bancos: el Banco del país del Comprador y el Banco en el país del Vendedor, sin embargo no es raro encontrar más Bancos participando de una misma transacción.

\subsubsection{Clases de Carta de Crédito}

\subsubsection{Según el compromiso asumido por el Banco Avisador}

- Confirmados: Cuando el Banco Avisador (y Confirmador) en el país del Beneficiario asume un compromiso en firme, adicional al del Banco Emisor, de pagar contra la presentación de documentos conformes.

Es una manera de reforzar las garantías para el Beneficiario, por lo que los Créditos Confirmados son muy utilizados en las transacciones internacionales.

En estos casos, el Banco Emisor le solicita a otro Banco que añada su confirmación, es para que se subrogue en las obligaciones que él tiene con el Beneficiario.

En una superposición de garantías, ya que si el Banco Emisor no cumpliera con los compromisos estipulados en la Carta de Crédito, por motivos no imputables al Beneficiario, el Banco Confirmador se compromete a pagar, aceptar o negociar los documentos.

Cabe señalar que la Confirmación del Crédito por un Banco corresponsal del Banco Emisor implica el encarecimiento del servicio para el Ordenante, por ello, la Confirmación del Crédito es generalmente un pedido del Vendedor. 
- $\quad$ No Confirmados: El Banco Avisador no añade compromiso alguno de su parte. Sólo se encuentra obligado al pago, el Banco Emisor. En este sentido, las funciones del Banco Avisador se limitan a dar fe de la autenticidad del documento de apertura, avisar al Beneficiario, recibir los documentos que le presente el Beneficiario y enviarlos al Banco Emisor, y recibir el pago del Banco Pagador, y entregarlo al Beneficiario.

Cabe señalar que si la Carta de Crédito es emitida por un Banco de primera línea, se hace innecesaria la Confirmación del Banco Intermediario, y se puede evitar un incremento de los gastos.

\subsubsection{Según el momento de ejecución}

- A la vista: El pago tiene que realizarse en el mismo momento en el que el Beneficiario presenta la documentación requerida en la Carta de Crédito, a excepción del tiempo estrictamente necesario para la revisión de los documentos.

En este sentido, el Banco Pagador deberá hacer efectiva la Carta de Crédito tan pronto como haya encontrado conformes los documentos presentados.

En el caso de que esta clase de Crédito Documentario implique una financiación por parte del Banco Pagador al Banco Emisor, el Banco Pagador debitará al Banco Emisor en una cuenta especial, llamada "Cuenta Adelanto" un monto equivalente al pago al Beneficiario. Los intereses que esta cuenta genere serán de cargo del Banco Emisor, y por lo general son transferidos al Ordenante, por ser el beneficiario indirecto del adelanto.

- $\quad$ De Pago Diferido: El pago no se realiza a la vista, sino en un plazo a contar desde un hecho cierto (por ejemplo, a partir de la Fecha de Embarque de las mercancías), o en una fecha futura prevista en el Crédito. En este sentido, el plazo puede estar señalado como:

- Vencimiento Fijo: Según fecha exacta estipulada en la Carta de Crédito.

- A Partir de la Fecha: el vencimiento será fijado teniendo en cuenta un cómputo de $X$ días a partir del suceso que se estipule, por ejemplo, desde la fecha del Conocimiento de Embarque, del Despacho de la mercancía, etc.

\subsubsection{Con relación al Beneficiario de la Transacción}

- Transferibles: El Beneficiario puede transferir la totalidad o parte del Crédito a terceros, llamados Segundos Beneficiarios, lo que impulsa la rapidez en el financiamiento para participar competitivamente en el comercio internacional.

Esta forma de Carta de Crédito es empleada con mucha frecuencia por los Agentes Intermediarios que compran productos a varios proveedores de su mismo país y los revenden a otro diferente. 
Conviene aclarar que la transferencia puede efectuarse una sola vez, es decir que ningún Segundo Beneficiario puede transferirlo nuevamente, a favor de uno tercero.

Sin embargo, no importa el número de Segundos Beneficiarios simultáneos ni las fechas de las Transferencias, siempre que todas estén dentro del tiempo de validez del crédito.

Las condiciones de estos créditos "Transferidos" deberán ser las mismas que las del Crédito Original, con la excepción del monto de éste, y de los vencimientos previstos, que pueden ser modificados en el Crédito Transferido, bajo la condición de que dichas modificaciones constituyan una disminución de los mismos.

Para que un Crédito se considere Transferible se debe señalarse expresamente dicha Transferibilidad.

- No Transferible: Cuando el Beneficiario no está facultado para transferirlo a un Segundo Beneficiario.

- $\quad$ Rotativos o "Revolving": Cuando los Créditos quedan automáticamente reabiertos una vez utilizados y en sus términos originales, por una o varias veces, y por el plazo que el propio Crédito haya determinado.

Para que los Créditos tengan esta condición se debe consignar expresamente en la Carta de Crédito a ser emitida. Se dividen a su vez en dos tipos:

- Acumulativos: los saldos no utilizados en el periodo anterior sirven para aumentar la cantidad disponible del periodo siguiente.

- No acumulativos: los importes que no se hayan empleado no se suman al periodo siguiente.

El Crédito Rotativo es un crédito que en cuanto es utilizado, se restablece en sus condiciones originales inmediata y automáticamente. Se emite generalmente a favor de un sólo Beneficiario y cubre varios embarques de una misma mercadería.

\subsubsection{Según las Facilidades Financieras}

- $\quad$ Respaldado o "Back to Back": Un Banco puede abrir una Carta de Crédito a pedido del Beneficiario de otra recibida con anterioridad (convirtiéndose este Beneficiario en nuevo Ordenante) a favor de su propio proveedor, con la garantía de ese primer crédito, pero independiente del mismo.

Podría solicitarse, cuando, por ejemplo, el Exportador recibe una Carta de Crédito a su favor pero no posee toda la mercancía que va a vender, pero con la garantía 
de la Carta de Crédito, el Banco Avisador le puede conceder otra a fin de que pueda abastecerse de la mercancía que necesita para cumplir con su obligación.

Es importante mencionar que en este caso, hablamos de dos Cartas de Crédito, cada una distinta e independiente de la otra.

A diferencia de la Carta de Crédito Transferible, la Carta de Crédito Back to Back le permite al Primer Beneficiario evitar que el Ordenante original se entere de la existencia de un Segundo Beneficiario, y asimismo, mantener en secreto (frente al Segundo Beneficiario) las condiciones originales de la Carta de Crédito así como la propia existencia del mismo.

- $\quad$ Con Cláusula Roja o "Red Clause": Permite anticipar al Beneficiario el pago de una parte del precio, la misma que debería ser utilizada en la fabricación de la mercancía o en adquirirla, si no fuera productor. Estos anticipos suelen traer algunas exigencias como entregar recibos justificantes de los importes recibidos por adelantado, antes de recibir dichos anticipos.

Los términos de la Carta de Crédito prevén su pago parcial o total contra un simple compromiso del Beneficiario de una entrega futura de la mercancía, otorgándose un adelanto al Beneficiario que pueda servirle para cumplir, a su vez, con una parte de los compromisos contraídos con sus propios proveedores, así como para pagar otros gastos relacionados con la Exportación que va a efectuar. La Carta de Crédito con Cláusula Roja supone, por consiguiente, un cierto grado de confianza entre el Importador y el Exportador.

Cabe señalar que en los casos en que el Crédito sea por el total del valor de la mercancía, el Crédito Documentario pierde su razón de ser ya que podría ser reemplazado por un Pago por Adelantado.

- $\quad$ Con Cláusula Verde o "Green Clause": Esta fórmula responde a una actitud más prudente que en el caso de la Carta de Crédito con Cláusula Roja.

En este caso, por el anticipo se exigen del Beneficiario, determinados documentos que le dan al Comprador el control de la mercadería, por ejemplo, puede exigir la entrega de Warrants o Certificados de Depósito por la mercadería, los mismos que son Títulos Valores representativos de la propiedad de la misma.

- $\quad$ Carta de Crédito "Stand By" o de Garantía: En castellano se le ha traducido como "Crédito de Contingencia" o "Carta de Crédito de Garantía". Hasta Diciembre de 1998 se regulaba según las RUU No. 500, pero hoy lo están según las International Stand by Practices (ISP 98), que regulan esta forma de Crédito desde el 1 de Enero de 1999. 
Es utilizada para respaldar operaciones de carácter financiero más que de carácter comercial. Se trata de un Crédito según el cual un Banco se obliga a pagar por orden de un Cliente, cierta suma a una Tercera Parte, en caso que dicho Cliente no cumpla con determinadas obligaciones contraídas con este Beneficiario. Es en verdad una garantía o seguro disfrazados de Crédito Documentario.

- $\quad$ Carta de Crédito Restringida: Cuando el cobro de una Carta de Crédito puede efectuarse en un determinado Banco Designado exclusivamente. Muchos Bancos Notificadores acostumbran agregar a la Notificación de las Cartas de Crédito que remiten a los Beneficiarios, la indicación de que los mismos pueden ser hechos efectivos únicamente por su intermedio.

Si cualquier Banco establecido en la plaza del Banco Notificador puede obtener del Banco Emisor la cobertura correspondiente, la Carta de Crédito no se considera Restringida, mientras que si contiene una indicación que limita al Banco Notificador la obtención de dicho cobertura, la Carta de Crédito será de este tipo. 